\title{
Guatteriopsis friesiana W. Rodrigues, nova espécie de Annonaceae para a Amazônia.
}

\author{
William A. Rodrigues (")
}

\section{Resumo}

Guatteriopsis friesiana W. Rodrigues (Annonaceae). arvoreta relativamente freqüente nas matas de terra firme das cercanias de Manaus, Amazonas, Brasil, é descrita neste trabalho como espécie nova. Inclui este artigo uma chave sinótica para identificaçāo das espécies de Guatteriopsis até então conhecidas

\section{INTRODUÇÃo}

Consultando a coleção de Annonaceae do herbário do INPA, casualmente deparei com alguns espécimes identificados por Fries como Xylopia cordata Fries, n. sp.

Verificando que essa nova espécie proposta por ele ainda continuava inédita e que, na verdade, era uma nova entidade, porém de gênero diferente, resolvi descrevê-la a seguir, dedicando-a ao nosso antigo e insigne ex-colaborador, R. E. Fries, como uma singela homenagem pelo muito que fez para o conhecimento dessa importante família de Annonaceae.

Guatteriopsis friesiana W. Rodrigues, n. sp. (Fig. 1)

Arbor parva 3-7 m. alta; ramuli juniores dense rufovillosi demum glabrescentes nigrescentesque, teretes. Folia $10-25 \mathrm{~cm}$ longa, $3,5-8,5 \mathrm{~cm}$ lata, disticha, anguste-elliptica vel obovato-elliptica, coriacea, subsessilia, ad basin cordata, ad apicem acuminata, discoloria, supra opaca, pallide-viridia, glabra, infra fulvescentia et sparsim adpresso-pilosa; costae supra subimpressae, glabrae infra prominentes; nervi secundarii utrimque 18-24, anastomosantes supra vix distincti, subtus prominuli; petioli $0,3-0,8 \mathrm{~cm}$ longi, incrassati juniores rufovillosi demum glabrescentes nigrescentesque. Alabrastra $0,9-2,0 \mathrm{~cm}$ longa, $0,7-1,2 \mathrm{~cm}$ larga, axillaria, solitaria elliptica vel ovalia, dense rufovillosa breviter pedunculata. Pedunculi 0,5-0,8 $\mathrm{cm}$ longi, rufovillosi ad basin bracteolati. Bracteolae foliaceae juniores rufovillosae.

(') - Instituto Nacional de Pesquisas da Amazônia,
Sepala 3 (raro 4), $1,0-1,2 \mathrm{~cm}$ longa, $0,5-0,8 \mathrm{~cm}$ lata, retrorsa, crassa, triangularia, acuta, rufovillosa, utrimque nigrescentia; petala 6 , subaequalia, crassa, 3 exteriora $1,7-2,3 \mathrm{~cm}$ longa, 0,8-1,0cm lata, ovalia, obtusa, utrimque dense rufovillosa, intra ad basin glabrescentia nigricantiaque; 3 interiora $1,5-1,8 \mathrm{~cm}$ longa, $0,6-0,8$ $\mathrm{cm}$ lata, lineare-oblonga vel ovata, ad apicem obtusiuscula, crassa, utrimque canovelutina, ad basin glabrescentia. Stamina numerosa, ca. $1,8 \mathrm{~mm}$ longa, flavescentia; filamenta brevissima, crassa, glabra; anthera linearia, extrorsa, connectivo supra loculos antherarum puberulento dilatato disciformi; carpella multa, subsessilia, conglutinata; ovaria rufovillosa; stili glabrescentes, breves; stigmata capitata, pilosa, conglutinata. Pedunculi fructiferi $0,7-1,0$ $\mathrm{cm}$ longi, crassi. Carpidia 6-8, 2,0-2,2cm longa, $0,7-0,8 \mathrm{~cm}$ in diameter, fusiformia, glabrescentia vel puberula, obtuso-acuminata, brevissime stipitata, rubra (ad maturitatem) unisperma. Semina $1,3-1,9 \mathrm{~cm}$ longa, $0,6-0,8 \mathrm{~cm}$ in diameter, nitida, badia, anguste-elliptica, ad basin leviter sulcata, vertice obtuso-acuminato.

Arvoreta de $3-7 \mathrm{~m}$ de altura, raminhos mais jovens densamente rufovilosos, mais tarde glabrescentes, enegrecidos, cilíndricos; foIhas de $10-25 \mathrm{~cm}$ de comprimento, $3,5-8,5 \mathrm{~cm}$ de largura, estreito-elípticas ou obovado-elípticas, coriáceas, subsésseis, cordadas na base, acuminadas no ápice, discolores, página superior opaca, verde-clara, página inferior castannoamarelada, revestida esparsamente de pêlos adpressos, nervura mediana subimpressa na página superior, saliente na página inferior, nervuras secundárias 18-24 dos dois lados, quase indistintas na página superior, anastomosadas, promínulas na página inferior; pecíolos de $0,3-0,8 \mathrm{~cm}$ de comprimento, grossos, rufotomentosos ou glabrescentes, enegrecidos. Botões florais de $0,9-2,0 \mathrm{~cm}$ de comprimento,

Manaus. 
0,7-1,2cm de largura, densamente rufovilosos, elípticos ou ovais, axilares, solitários, curtamente pedunculados. Pedúnculos de $0,5-0,8 \mathrm{~cm}$ de comprimento, rufovilosos, bracteolados na base, bractéolas foliáceas, as mais novas rufovilosas. Sépalas 3, (raro 4), de 1,0-1,2cm de comprimento, $0,5-0,8 \mathrm{~cm}$ de largura, retrorsas, espessas, triangulares, agudas, rufovilosas, escurecidas em ambas as faces; pétalas 6 , desiguais, espessas, as 3 exteriores de $1,7-2,3 \mathrm{~cm}$ de comprimento, $0,8-1,0 \mathrm{~cm}$ de largura, ovais, obtusas, côncavas, densamente rufovilosas em ambas as faces, internamente glabrescentes e enegrecidas na base; as 3 internas de $1,5-1,8 \mathrm{~cm}$ de comprimento, $0,6-0,8 \mathrm{~cm}$ de largura, linearoblongas, ou ovais, obtusiúsculas no ápice, espessas, canovelutinas em ambas as faces, glabrescentes na base. Estames numerosos; de ca. $1,8 \mathrm{~mm}$ de comprimento, verde-amarelados, filamentos muito curtíssimos, espessados, glabros; anteras lineares, extrorsas, conectivo puberulento e dilatado em forma de disco ou

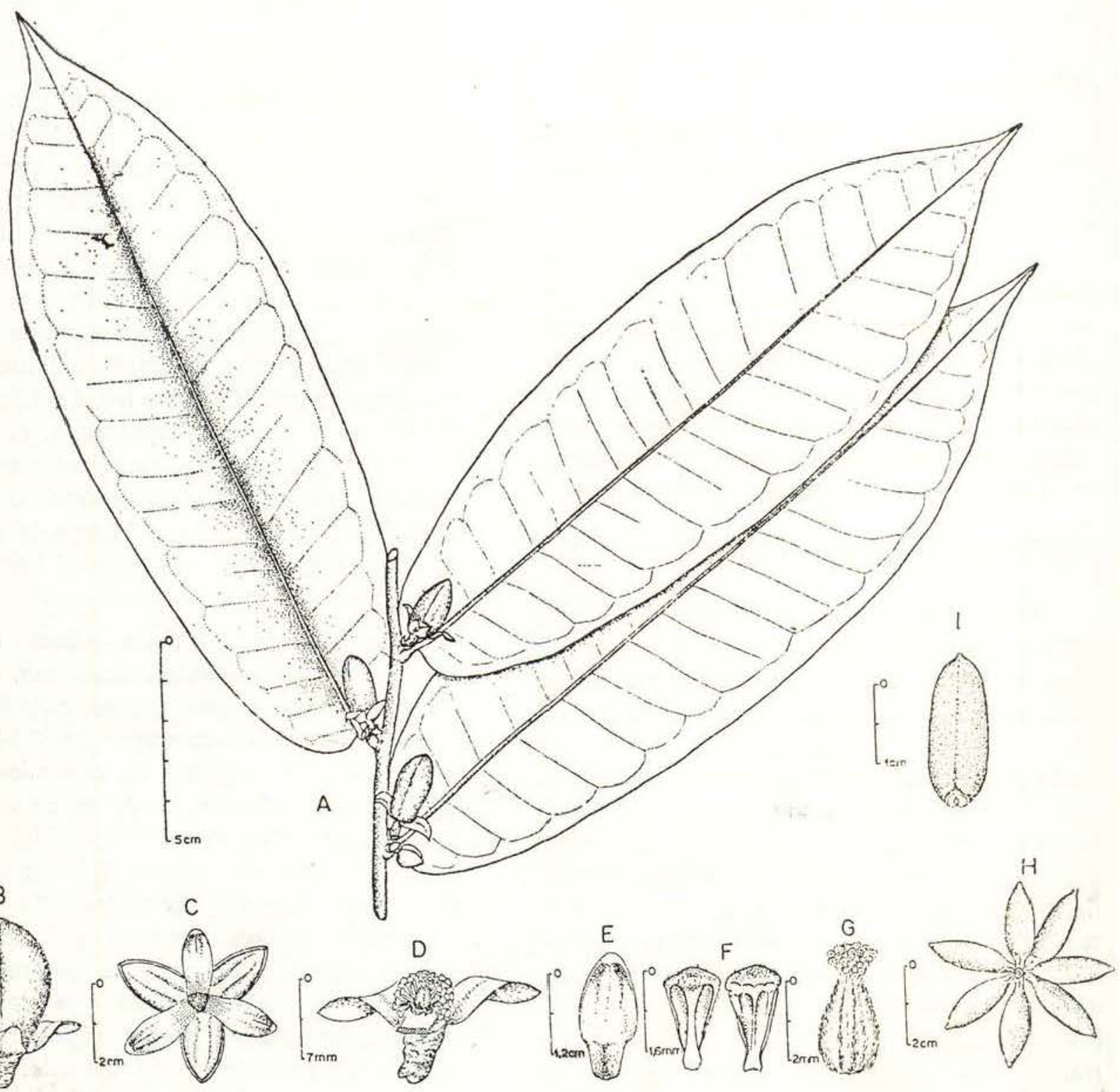

Fig. 1 - Guatteriopsis friesiana W. Rodrigues, n, sp. A - (L. F. Coelho s/n. INPA 3609): ramo florifero; B - I (D. F. Coelho \& J. Ramos s/n. INPA 92465): B - botão floral; C - flor aberta; D - mostrando o pistilo e androceu; E - pétala interna; F - estames; G - pistilo; H - frutos; 1 - semente. (Desenho de William Leite). 
capuz acîma dos fócufos; carpefos vârios, subsésseis; ovários rufovilosos, estiletes glabrescentes, curtos; estígmas capitados, pilosos, conglutinados. Pedúnculo frutífero de $0,7-1,0$ $\mathrm{cm}$ de comprimento, grosso; carpídios 6-8, 2,0-2,2cm de comprimento, $0,7-0,8 \mathrm{~cm}$ de diâmetro, fusiformes, glabrescentes ou pubérulos, obtuso-acuminados, curtissimamente estipitados, vermelhos (quando maduros), unispermos, sementes de $1,3-1,9 \mathrm{~cm}$ de comprimento, 0,6-0,8 $\mathrm{cm}$ de diâmetro, nítidas, castanho-escuras, estreitamente elípticas, ligeiramente sulcadas na base, obtuso-acuminadas no vértice.

TIPOS: Brasil-Amazonas, Manaus: igarapé do Passarinho. Árvore de $6 \mathrm{~m}$; mata de terra firme, solo argiloso. Flores castanho-amareladas. D. Coelho $\mathrm{s} / \mathrm{n}$. fl. 14 março 1956 (Holótipo INPA 3609); ibidem: margem do igarapé Tabatinga. Arbusto de $3 \mathrm{~m}$, mata de terra firme; flores marrons. J. Chagas de Almeida s/n. fl. 7 fev. 1955 (INPA 783); ibidem: $\mathrm{km} 70$ da estrada Manaus-Itacoatiara (BR-17). Arvoreta de $5 \mathrm{~m}$, mata de terra firme, solo argiloso; flores amarelas. $W$. Rodrigues 2609, fl. e fr. 17 maio 1961 (INPA 9152); ibidem: km 55, ZF-1, varadouro de ligação com a Manaus-Caracaraí. Arvoreta de $5 \mathrm{~m}$ de altura; flores com pétalas verde-ferruginosas $\mathrm{e}$ estames verde-amarelados; frutos maduros vermelhos e imaturos, verdes. D. Coelho \& J. Ramos $s / n$., fl. e fr. 15 maio 1980 (INPA 92465); ibidem: Reserva Florestal Ducke, picada da Petrobrás. Árvore de $7 \mathrm{~m}$ por $6 \mathrm{~cm}$ de diâmetro, mata de terra firme, solo arenoso; frutos ainda verdes; nome vulgar: envireira. W. Rodrigues \& A. Loureiro 5908, fr. 12 jun. 1964 (INPA 14852); ibidem: rio Cuieiras-Manaus trail, $\mathrm{km} \mathrm{1.} \mathrm{Prima-}$ ry forest on terra firme. Treelet, $3 \mathrm{~m}$ tail. Buds green. Calyx and corolla golden with velvety pubescence. $D$. G. Campbell, J. C. Ongley \& J. F. Ramos P21896, fl. e fr. 6 abr. 1974. (INPA 45836; NY).

Guatteriopsis friesiana distingue-se facilmente das outras 4 espécies do gênero espe- cialmente pelas folhas discolores e cordadas na base, e de G. kuhlmannii Fries, particularmente, pela forma do botão floral.

As 5 espécies até então conhecidas de Guatteriopsis podem ser facilmente distinguidas de acordo com a chave sinótica a seguir.

\section{CHAVE SINÓTICA DE IDENTIFICAÇĀO DAS} ESPÉCIES DE GUATTERIOPSIS R. E. FRIES.

I - Revestimento adpresso

2) Lâmina foliar estreitando-se em direção à base.

3) Folhas mais ou menos oblongas. estreitando-se bastante rapidamente na base. Carpídios alongados, ovais, arredondados no ápice.

1) G. sessiliflora (Benth.) R. E. Fries

3) Folhas oblanceoladas, estreitandose em forma de cunha em direção à base. Carpídios fusiformes, estreitados em ambas as extremidades.

2) G. blepharophylla (Mart.) R. E. Fries

2) Lâmina foliar arredondada ou cordada na base.

4) Lâmina arredondada na base.

3) G. kuhlmannii R. E. Fries.

4) Lâmina cordada na base.

4) G. friesiana W. Rodrigues

II - A axila dos ramos jovens, parte inferior das folhas e os frutos revestidos com pêlos compridos, eretos. Carpídios fusiformes.

5) G. hispida R. E. Fries

\section{SUMMARY}

Guatteriopsis friesiana W. Rodrigues is described as a new species of Annonaceae, which is readily separated from the other 4 species of the same genus especially by its leaves discolour and cordate at the base and in particular from G. kuhlmannii Fries by the outline of its flower buds.

A synoptical key for identification of the species of Guatteriopsis is included.

(Aceito para publicação em 01/10/80) 